\title{
MECHANICAL PROPERTIES OF S355 UNDER EXTREME COUPLED EFFECT OF HIGH TEMPERATURES AND HIGH STRAIN RATES
}

\author{
Daniele Forni $^{1,2}$, Bernardino Chiaia $^{2}$, Ezio Cadoni ${ }^{1}$ \\ ${ }^{1}$ DynaMat Lab, University of Applied Sciences of Southern Switzerland \\ CH-6952 Canobbio, Switzerland \\ e-mail: daniele.forni@supsi.ch \\ e-mail: ezio.cadoni@supsi.ch \\ ${ }^{2}$ Department of Structural, Geotechnical and Building Engineering, Politecnico di Torino \\ Torino, Italy \\ e-mail: bernardino.chiaia@polito.it
}

Keywords: Robustness, fire induced progressive collapse, S355 structural steel, high strainrates, high temperatures, Johnson-Cook constitutive law.

\begin{abstract}
With the intention of focusing the attention on the extreme combined effects of temperature and dynamic loadings, the high strain rate behaviour in tension of the widely used S355 structural steel in a wide range of elevated temperatures is presented.

By means of a Split Hopkinson Tensile Bar (SHTB) equipped with a water-cooled induction heating system, the main mechanical properties as well as different strain energy densities have been evaluated. The reduction factors for the main mechanical properties, in which the novelty of our data is the addition of the strain rate dependency to the temperature, are reported as well. Lastly, a critic review of the Johnson-Cook constitutive law has been reported, highlighting that the use of single averaged thermal softening parameter $(m)$ could lead to considerable errors. These results could be of great interest for the assessment of robustness in structures subjected to fire induced progressive collapse.
\end{abstract}




\section{INTRODUCTION}

An extended exposure to high temperatures may severely influence the performance of the steel framed structures triggering for example a fire induced progressive collapse.

Even if the progressive collapse became an important topic after the partial collapse of the Ronan Point Building (UK) in 1968 [1, 2, 3], only after the 9/11 World Trade Center tragedy $[4,5]$ a significant amount of research has been carried out to assess the fire resistance and to predict the blast response of steel structures. But, only uncorrelated effects of dynamic loadings and high temperatures have been considered [6]. For that reason the mechanical response of steel structures subjected to extreme combined effects has still criticisms open to investigation.

With the intention of fulfilling these criticisms, the mechanical behaviour of a widely used structural steel, namely S355, in a wide range of temperatures $\left(200^{\circ} \mathrm{C}, 400{ }^{\circ} \mathrm{C}, 550{ }^{\circ} \mathrm{C}, 700^{\circ} \mathrm{C}\right.$ and $900{ }^{\circ} \mathrm{C}$ ) and high strain rates will be presented. The results can be of great interest for the assessment of robustness in structures where a progressive collapse is triggered by a coupled effect of fire and dynamic loadings.

\section{PROGRESSIVE COLLAPSE: CHOICE OF THE APPROACH}

Two approaches are known for studying the progressive collapse, namely the indirect and the direct methods. While for the first, the designers may use an implicit design, in the second the designers need to perform a structural analysis. Two typical used direct methods are the specific local resistance method (known also as key element design) and the alternate load path.

Another approach that should be followed is based on the employment of discrete element method (DEM) models. An extensive research in this field has been performed by Masoero et al. [7, 8, 9], that demonstrated the DEM's applicability to progressive collapse by simulating the behaviour of 2D and 3D framed structures after a sudden damage.

Focusing the attention on the direct methods we should not forget the analytical procedure that can be used to model the problem. Although simplified hypotheses are supposed, like linear static or non-linear static analysis as well as linear dynamic analysis, the most rigorous approach for evaluating a progressive collapses is through the use of an explicit non-linear $d y$ namic procedure. But, even if the non-linear dynamic procedure is the most accurate approach, another fundamental aspect should be taken into consideration: the real mechanical properties of the material subjected to extreme combined loadings [10].

With the intention of evaluating the structural performance in response of a coupled effect of fire and blast loading, one of the most commonly implemented [11, 12, 13] and easy-to-use constitutive relationships in the finite element programs is here considered. This constitutive model has been proposed by Johnson and Cook during the eighties [14] and is widely used to describe the material strength in numerical simulations of dynamic events. The flow stress can be expressed as:

$$
\sigma=\left(A+B \cdot \epsilon_{p}^{n}\right) \cdot\left(1+c \cdot \ln \frac{\dot{\epsilon}}{\dot{\epsilon}_{0}}\right) \cdot\left(1-T^{* m}\right)
$$

where $\epsilon_{p}$ is the true plastic strain, $\dot{\epsilon}$ is the considered strain rate, $\dot{\epsilon}_{0}$ is the reference strain rate (taken as $1 \mathrm{~s}^{-1}$ ) and $T^{*}$ is a dimensionless temperature. In order to find the Johnson-Cook parameters $A, B$ and $n$ [15], representing the strain hardening effects of the material in quasistatic conditions, $c$ [15] representing the strain rate sensitivity and $m$ [16] representing the thermal softening sensitivity, a mechanical characterisation in a wide range of temperatures and high strain rates is necessary. 


\section{MECHANICAL CHARACTERISATION AT HIGH STRAIN-RATES AND HIGH TEMPERATURES}

The mechanical characterisation at high strain-rates was carried out by means of a Split Hopkinson Tensile Bar (SHTB) installed at the DynaMat Laboratory [17]. The tests at elevated temperatures were performed by using an Ambrell compact EASYHEAT induction water-cooled heating system (Figure 1). A detailed description of the functioning of the SHTB equipped with the induction water-cooled heating system has been given in [16].

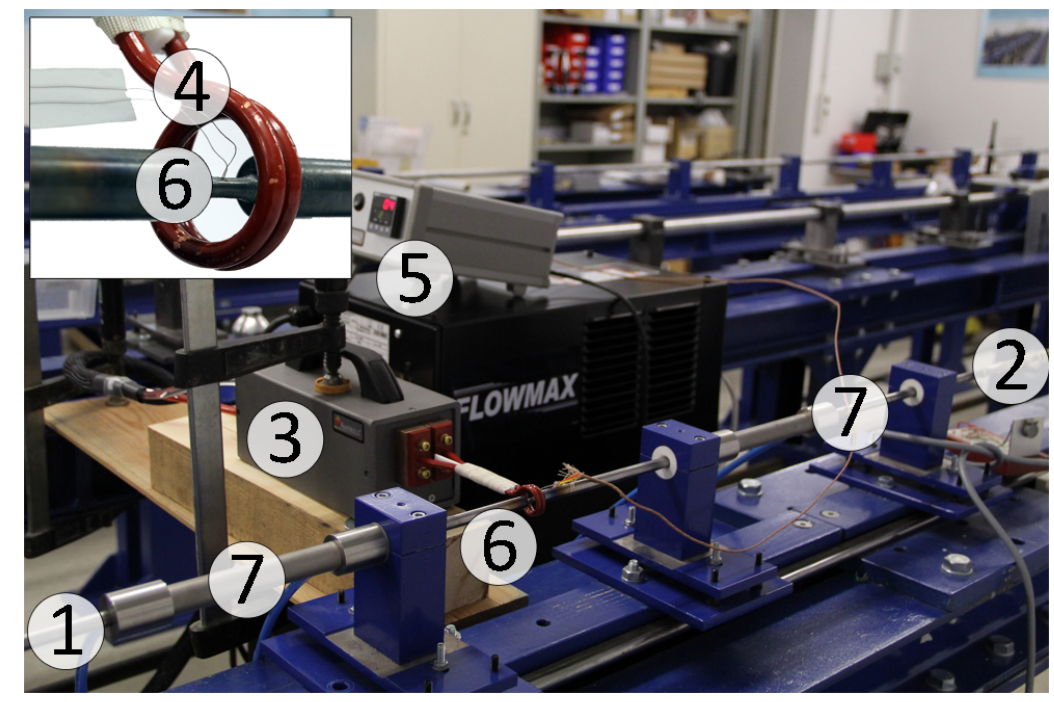

Figure 1: Setup for the high strain rate tests at elevated temperature: (1) the input bar, (2) the output bar, (3) the heating system, (4) the water-cooled induction coil, (6) the sample to be tested connected by means of a thermocouple to a (5) thermal controller and (7) the cooling system for the input and output bars, respectively.

The specimens for the mechanical characterisation were obtained in the longitudinal direction from an hot-rolled wide-flange section HE A [18]. Starting from the initial section geometry, wire electrical discharge machining (WEDM) was used in order to obtain small prismatic samples, that where turned in order to obtain round samples with $3 \mathrm{~mm}$ in diameter and $5 \mathrm{~mm}$ of gauge length. A full description of the geometry is reported in [19, 20].

In order to understand the effect of the temperature on the dynamic mechanical properties of the S355 structural steel, the high strain rate tests at elevated temperatures were performed with the same testing conditions adopted at room temperature. With these testing conditions and at $20^{\circ} \mathrm{C}$, the obtained averaged strain rates were approximately $300 \mathrm{~s}^{-1}\left(v_{1}=2.30 \mathrm{~m} / \mathrm{s}\right), 500 \mathrm{~s}^{-1}$ $\left(v_{2}=2.90 \mathrm{~m} / \mathrm{s}\right)$ and $850 \mathrm{~s}^{-1}\left(v_{3}=4.00 \mathrm{~m} / \mathrm{s}\right)$. The corresponding particle velocities in the input bar, used as a reference for the testing condition, are reported within brackets.

Additional tests were also performed by compensating the preload with the intention of obtaining tests with comparable effective strain rate. This has been helpful for the calibration of the Johnson-Cook thermal softening sensitivity parameter $(m)$.

\section{RESULTS}

Due to the different mechanical properties of steel at elevated temperatures, an increase of the reflected pulses is noted for increasing temperatures (Figure 2 left). This lead to a noticeable increase in the averaged strain rate at different temperatures (Figure 2 right).

The temperature effect on the mechanical properties of the S355 structural is represented in Figure 3, where the engineering stress versus strain and the true stress versus strain represen- 

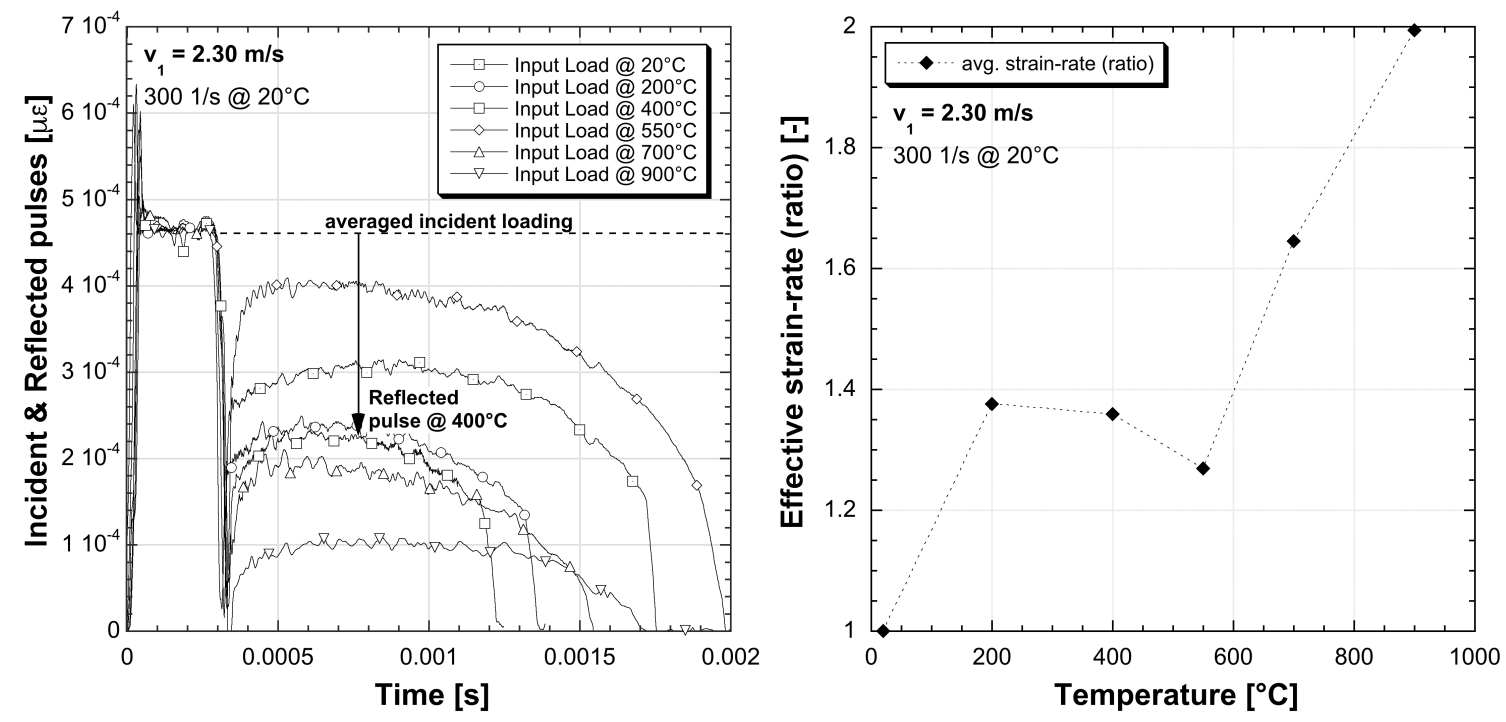

Figure 2: Comparison of reflected pulses at increasing temperatures (left) and effective strain-rate for increasing temperatures (rigth) for a fixed testing condition $\left(v_{1}=2.30 \mathrm{~m} / \mathrm{s}\right)$.

\begin{tabular}{cccc}
\hline $\begin{array}{c}\mathbf{A} \\
(\mathrm{MPa})\end{array}$ & $\begin{array}{c}\mathbf{B} \\
(\mathrm{MPa})\end{array}$ & $\begin{array}{c}\mathbf{n} \\
(-)\end{array}$ & $\begin{array}{c}\mathbf{c} \\
(-)\end{array}$ \\
\hline 448 & 782 & 0.562 & 0.0247 \\
\hline
\end{tabular}

Table 1: Johnson-Cook parameters obtained at room temperature [15].

tative plots are depicted. In Figure 4 the post-mortem images of the samples tested at different temperatures are reported.

Another way of comparing the tensile properties at different temperatures is by means of a reduction factor determined as the ratio of the value at elevated temperatures to the corresponding value at room temperature. The reduction factors for the proof strength and the ultimate tensile strength evaluated at high strain rates are reported in Figure 5. It is possible to observe that the reduction factor proposed by the Eurocode 3 [21] for the proportional limit in quasistatic conditions is not applicable for the high strain-rate tests, while the reduction factors seem not to be strongly different for the three testing conditions. The reduction factors for the other mechanical properties are reported in [16].

\section{CONSTITUTIVE MODEL}

The Johnson-Cook parameters evaluated by means of tests at room temperature are reported in Table [15], while the experimental data at different temperatures and for a fixed strain rate $\left(450 \mathrm{~s}^{-1}\right)$ were used to determine [16] the thermal softening sensitivity parameters (Table 2).

In a previous study by the current authors [16], a thermal softening factor obtained experimentally at different temperatures was defined $\left(\mathrm{R}^{*}\right)$. In Figure 6 a comparison between this

\begin{tabular}{ccccc}
\hline \multicolumn{5}{c}{$\mathbf{m}\left(450 \mathrm{~s}^{-1}\right)$} \\
$200{ }^{\circ} \mathrm{C}$ & $400{ }^{\circ} \mathrm{C}$ & $550{ }^{\circ} \mathrm{C}$ & $700{ }^{\circ} \mathrm{C}$ & $900{ }^{\circ} \mathrm{C}$ \\
$(-)$ & $(-)$ & $(-)$ & $(-)$ & $(-)$ \\
\hline 0.551 & 0.675 & 0.988 & 0.953 & 0.454 \\
\hline
\end{tabular}

Table 2: Johnson-Cook thermal softening sensitivity parameters at different temperatures [16]. 

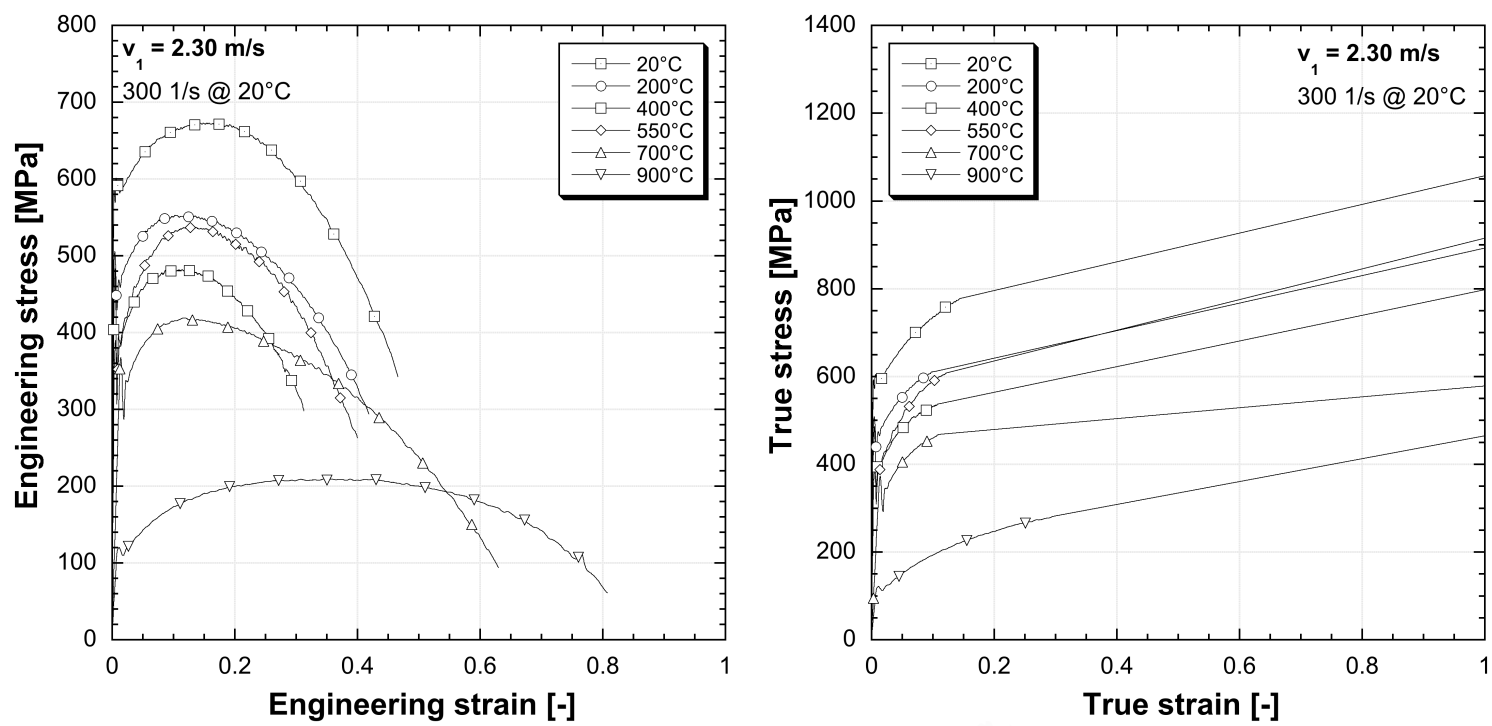

Figure 3: Comparison of engineering stress-strain curves (left) and true stress-strain curves (right) at different temperatures.
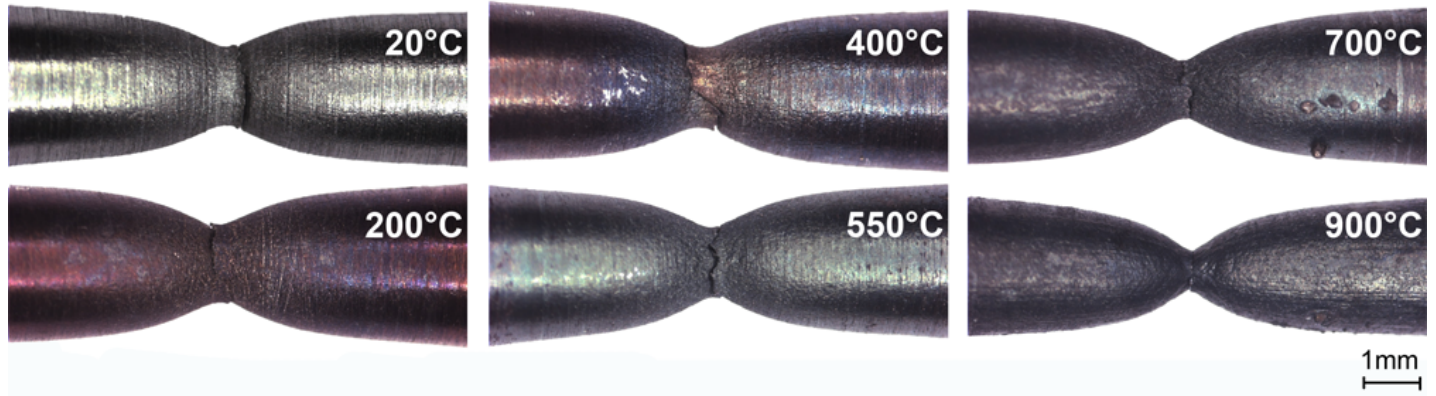

Figure 4: Reduction of area of samples tested at elevated temperatures.
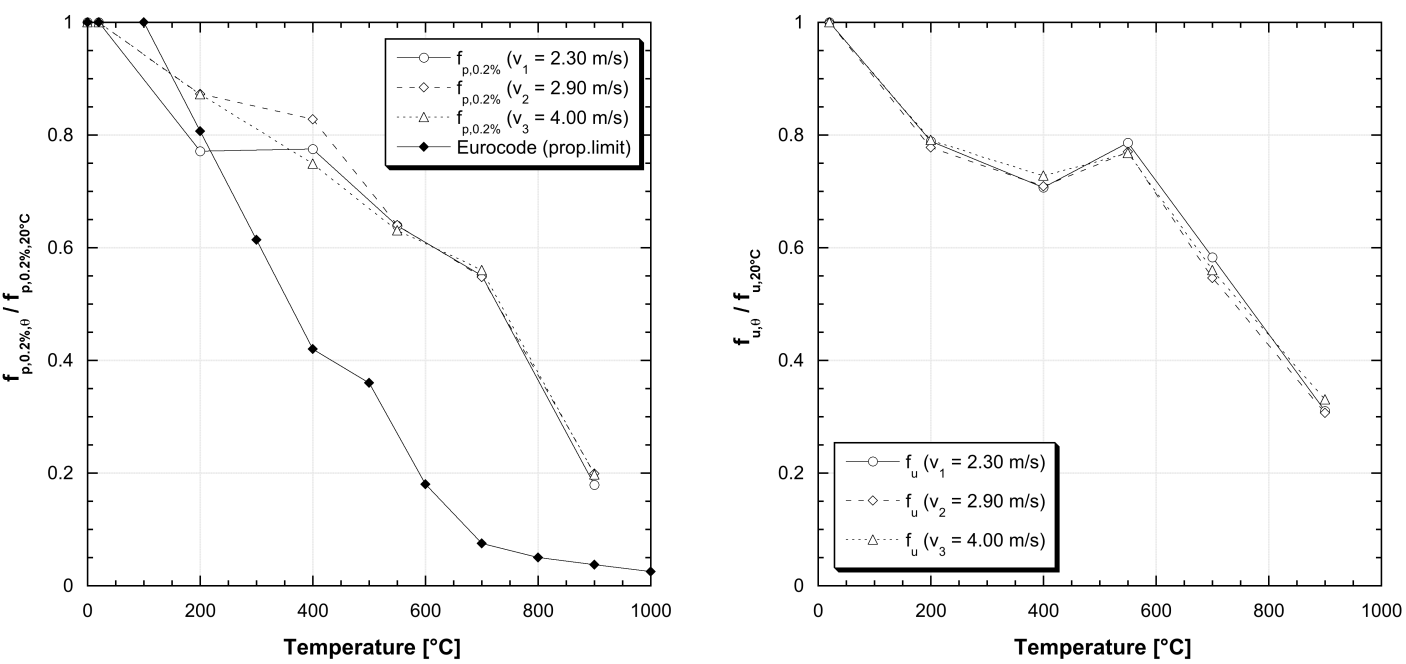

Figure 5: Reduction factors for the proof strength (left) and the ultimate tensile strength (right). 
factor and the thermal factor of the Johnson-Cook constitutive law $\left(1-T^{* m}\right)$ with fixed single values of $m$ is reported. It is possible to observe that single averaged values of $m$ obtained by comparing only two sets of data from room temperature and a single high temperature, could lead to considerable errors.

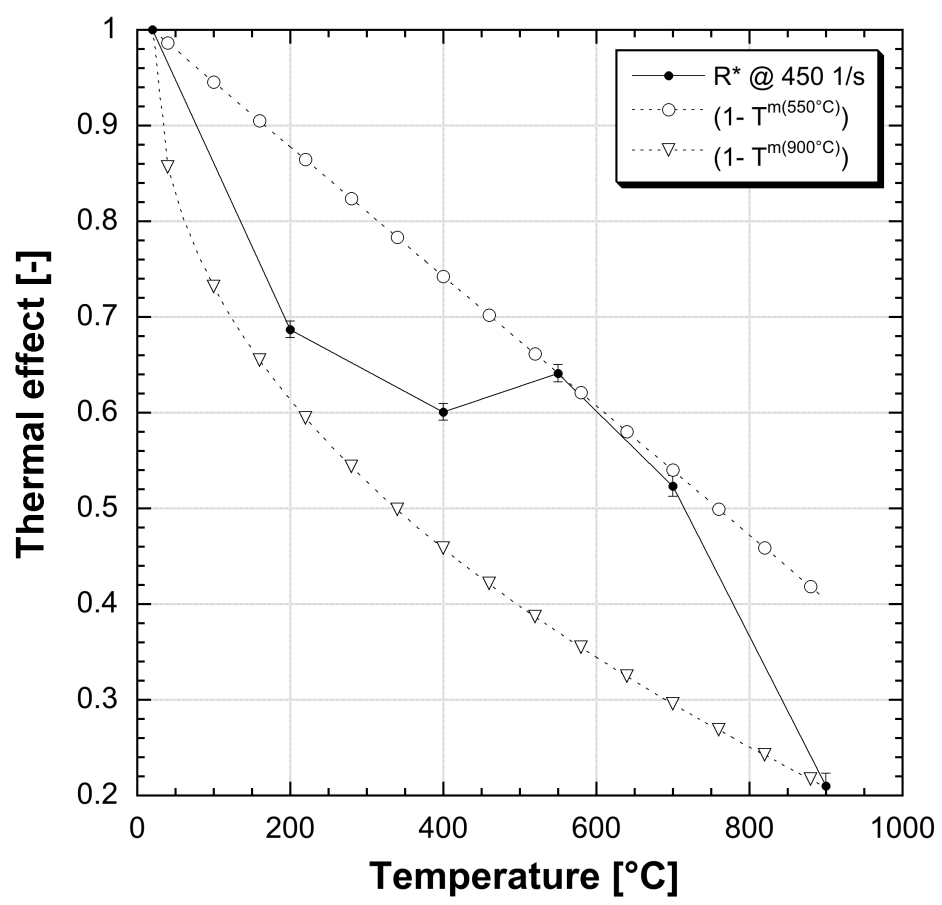

Figure 6: Comparison between the thermal softening factors obtained experimentally and the thermal factor of the Johnson-Cook constitutive law with fixed single values of $m$.

\section{CONCLUSIONS}

In this paper the high strain rate behaviour in tension of the widely used S355 structural steel in a wide range of elevated temperatures has been presented.

- Due to the different mechanical properties of steel at elevated temperatures, a perceptible increase in the effective strain rate was observed.

- The tensile properties were not significantly influenced by the different dynamic testing conditions.

- A remarkable difference between quasi-static and high strain rate reduction factors was highlighted.

- A perceptible variation of the thermal softening parameter $(m)$ was highlighted.

- Using a single averaged value of $m$ could lead to considerable errors.

These findings could be helpful in order to simulate the effect of a dynamic loading, e.g. an explosion, on steel structural elements under different temperatures. As a future development a numerical simulation will be implemented in Ls-Dyna considering the material properties of the structural steel S355 at high temperatures and high loading rates. 


\section{ACKNOWLEDGEMENTS}

This work is part of research project Behaviour of structural steels under fire in a wide range of strain rate founded by the State Secretariat for Education, Research and Innovation of the Swiss Confederation (project C12.0051), in the frame of the COST ACTION TU0904 Integrated Fire Engineering and Response (IFER).

\section{REFERENCES}

[1] C. Pearson and N. Delatte. Ronan point apartment tower collapse and its effect on building codes. Journal of Performance of Constructed Facilities, 19(2):172-177, 2005.

[2] J.B. Menzies and D.A. Nethercot. Progressive collapse - preventive measures in the united kingdom. Proceedings of the Structural Engineers World Congress, San Francisco, USA, 1998.

[3] A. Longinow and B.R. Ellinwood. The impact of the ronan point collapse - 25 years after. Proceedings of the Structural Engineers World Congress, San Francisco, USA, 1998.

[4] Z.P. Bazant and Y. Zhou. Why did the world trade center collapse? - Simple analysis. Journal of Engineering Mechanics, 128(1):2-6, JAN 2002.

[5] Z.P. Bazant and M. Verdure. Mechanics of progressive collapse: Learning from world trade center and building demolitions. Journal of Engineering Mechanics, 133(3):308319, MAR 2007.

[6] J.Y. Richard Liew. Survivability of steel frame structures subject to blast and fire. Journal of Constructional Steel Research, 64(7-8):854 - 866, 2008.

[7] E. Masoero, F.K. Wittel, H.J. Herrmann, and B.M. Chiaia. Progressive collapse mechanisms of brittle and ductile framed structures. Journal of Engineering Mechanics, 136(8):987-995, 2010.

[8] E. Masoero, F.K. Wittel, H.J. Herrmann, and B.M. Chiaia. Hierarchical structures for a robustness-oriented capacity design. Journal of Engineering Mechanics, 138(11):1339_ 1347, 2012.

[9] E. Masoero, P. Darò, and B.M. Chiaia. Progressive collapse of $2 \mathrm{~d}$ framed structures: An analytical model. Engineering Structures, 54:94-102, 2013.

[10] H.M. Elsanadedy, T.H. Almusallam, Y.R. Alharbi, Y.A. Al-Salloum, and H. Abbas. Progressive collapse potential of a typical steel building due to blast attacks. Journal of Constructional Steel Research, 101(0):143 - 157, 2014.

[11] E. Cadoni, M. Dotta, D. Forni, and S. Bianchi. Strain-rate effect on the tensile behaviour of high strength alloys. Applied Mechanics and Materials, 82:124-129, 2011.

[12] E. Cadoni, M. Dotta, D. Forni, and N. Tesio. Dynamic behaviour of reinforcing steel bars in tension. Applied Mechanics and Materials, 82:86-91, 2011.

[13] E. Cadoni, M. Dotta, D. Forni, and N. Tesio. High strain rate behaviour in tension of steel B500A reinforcing bar. Materials and Structures, pages 1-11, 2015. 
[14] G.R. Johnson and W.H. Cook. Fracture characteristics of three metals subjected to various strains, strain rates, temperatures and pressures. Engineering Fracture Mechanics, 21(1):31-48, 1985.

[15] D. Forni, B. Chiaia, and E. Cadoni. Strain rate behaviour in tension of S355 steel: base for progressive collapse analysis. Submitted to Engineering Structures (2015), 2015.

[16] D. Forni, B. Chiaia, and E. Cadoni. High strain rate response of S355 at high temperatures. Materials \& Design, 94:467 - 478, 2016.

[17] E. Cadoni, M. Dotta, D. Forni, N. Tesio, and C. Albertini. Mechanical behaviour of quenched and self-tempered reinforcing steel in tension under high strain rate. Materials \& Design, 49(0):657 - 666, 2013.

[18] M. Knobloch, J. Pauli, and M. Fontana. Influence of the strain-rate on the mechanical properties of mild carbon steel at elevated temperatures. Materials \& Design, 49:553 $565,2013$.

[19] E. Cadoni, M. Dotta, D. Forni, and P. Spaetig. Strain-rate behavior in tension of the tempered martensitic reduced activation steel EUROFER97. Journal of Nuclear Materials, 414(3):360 - 366, 2011.

[20] E. Cadoni, L. Fenu, and D. Forni. Strain rate behaviour in tension of austenitic stainless steel used for reinforcing bars. Construction and Building Materials, 35(0):399 - 407, 2012.

[21] Eurocode 3 (2005) - Design of steel structures. Part 1-2: General rules - Structural fire design. 2005. 